Gerald T. Montague

NYMA, Inc.

Engineering Services Division

Brook Park, OH 44142

Albert F. Kascak
Vehicle Propulsion Directorate
U.S. Army Research Laboratory
Lewis Research Center
Cleveland, OH 44135

Alan Palazzolo

Daniel Manchala

Erwin Thomas

Texas A\&M University

College Station, TX 77843

\title{
Feedforward Control of Gear Mesh Vibration Using Piezoelectric Actuators
}

\begin{abstract}
This article presents a novel means for suppressing gear mesh related vibrations. The key components in this approach are piezoelectric actuators and a high-frequency, analog feedforward controller. Test results are presented and show up to a $70 \%$ reduction in gear mesh acceleration and vibration control up to $4500 \mathrm{~Hz}$. The principle of the approach is explained by an analysis of a harmonically excited, general linear vibratory system. (c) 1994 John Wiley \& Sons, Inc.
\end{abstract}

\section{INTRODUCTION}

Transmissions can generate vibrations and noise by many mechanisms. Inherent in the transmission of motion with gears is the time-varying gear mesh stiffness as the number of teeth and position of load changes along the tooth profile. Many other factors can also contribute to the resultant level of vibration or noise found at the gear mesh frequency. Examples of these controllable factors include shaft misalignment or gear manufacturing errors, such as pitch runout or profile errors. Therefore, the gear meshing action can be minimized by proper profile manufacture, proper assembly, and tight tolerances on the support structure, but the gear mesh vibration or noise cannot be completely avoided.

Gear mesh vibrations are transmitted from the gear to the shaft and through the bearings to the case. A novel approach to reduce transmission vibrations is to apply a force with piezoelectric actuators at the bearing outer race. This method has evolved from the application of piezoelectric actuators for active vibration control of rotating machinery. Prior research has used piezoelectric actuators to control subsynchronous, synchronous, and transient rotor vibrations (Palazzolo et al., 1993).

Previous work has concentrated on developing an actuator with a small envelope exciter, high-frequency range, and high-force capability (Palazzolo et al., 1993). The configuration consisted of a piezoelectric actuator driving an input piston contained in a hydraulic line. The output piston applies forces to the shaft through a ball bearing.

This research applies piezoelectric actuators to control a high-frequency $(4500 \mathrm{~Hz})$ gear mesh 
vibration component. Active control of high-frequency vibration is in contrast to passive gear vibration control using viscoelastic damping materials (Ren et al., 1990). Gear vibration can be reduced by introducing coulomb damping to the radial motion of the rim (Botsford, 1980). A systematic approach to reduce gear noise by improving the gear train structure rather than by focusing on the excitation forces of individual gears has been presented by Ariga et al. (1992). Nagamatsu et al. (1979) performed a theoretical vibration analysis of a casing for a high-speed rotating machine using the reduced impedance method. Choy et al. (1993) developed a dynamic model to simulate gearbox vibration and used experimental results from a test rig to verify the analytical model. Umezawa et al. (1988) developed a method to estimate the vibration of encased gears by measuring exterior vibration. The work of Umezawa et al. (1988) demonstrated that the transfer function obtained from impact testing while the nonrotating gear was under a static torque can be used for the estimation of gear vibration. Gear vibration monitoring techniques were reviewed by Mathew and Alfredson (1987) on a test rig. They deliberately induced gear damage by eliminating lubrication, applying excessive torque, and introducing dust in the gearbox.

The objective of this research was to apply feedforward control to a transmission test rig using piezoelectric actuators to reduce gear mesh vibration. The experimental research was conducted on a four-square spur gear transmission test rig at the NASA Lewis Research Center. Active control of gear mesh vibration was performed with various torque, speed, and actuator conditions. The details and results of these tests are presented herein.

\section{THEORY}

The operating principle for the feedforward active vibration controller may be explained by considering the dynamic equilibrium equations for a general linear system

$$
[M] \ddot{\mathbf{X}}+[C] \dot{\mathbf{X}}+[K] \mathbf{X}=\mathbf{F}_{D}+\mathbf{F}_{C}
$$

where $[M]=$ mass matrix; $\ddot{\mathbf{X}}=$ second derivative of displacement vector; $[C]=$ damping matrix $; \dot{\mathbf{X}}=$ first derivative of displacement vector; $[K]=$ stiffness matrix $\mathbf{X}=$ displacement vector; $\mathbf{F}_{D}=$ external force vector (disturbance or gear mesh forces); $\mathbf{F}_{C}=$ feedforward control force vector. The gear mesh and control forces will be at the gear mesh frequencies; hence

$$
[M] \ddot{\mathbf{X}}+[C] \dot{\mathbf{X}}+[K] \mathbf{X}=\hat{\mathbf{F}}_{D} e^{i \omega t}+\hat{\mathbf{F}}_{c} e^{i \omega t}
$$

where $\hat{\mathbf{F}}_{D}=$ complex vector of the disturbance force phasors; $i=$ square root of $-1 ; \omega=$ gear mesh frequency; $t=$ time; $\hat{\mathbf{F}}_{C}=$ complex vector of control force phasors. Setting

$$
\mathbf{X}=\hat{\mathbf{X}} e^{i \omega t}
$$

where $\hat{\mathbf{X}}$ is a complex vector of the displacement phasors, yields

$$
\left(-\omega^{2}[M]+i \omega[C]+[K]\right) \hat{\mathbf{X}}=\hat{\mathbf{F}}_{D}+\hat{\mathbf{F}}_{C}
$$

This may be solved for $\hat{\mathbf{X}}$ as

$$
\hat{\mathbf{X}}_{C}=\hat{\mathbf{X}}_{o}+\alpha \hat{\mathbf{F}}_{C}
$$

where $\hat{\mathbf{X}}_{C}=$ displacement vector phasor with control;

$$
\hat{\mathbf{X}}_{o}=[\alpha] \hat{\mathbf{F}}_{D}
$$

is the displacement vector phasor without control;

$$
[\alpha]=\left(-\omega^{2}[M]+i \omega[C]+[K]\right)^{-1}
$$

is the influence coefficient matrix; $\alpha=$ influence coefficient.

Note the case where a single control force $\hat{\mathbf{F}}_{c j}$ is applied at degree of freedom $j$ and the response is considered at a degree of freedom $i$ :

$$
\hat{\mathbf{X}}_{c i}=\hat{\mathbf{X}}_{o i}+\alpha_{i j} \hat{\mathbf{F}}_{c j}
$$

The control force that nulls the response at degree of freedom $i$ is obtained by solving Eq. (8) with $X_{c i}$ set to 0:

$$
\mathbf{F}_{c j}=-\mathbf{X}_{o i} / \alpha_{i j}
$$

Alternatively, $F_{c j}$ is the control force that makes

$$
\alpha_{i j} \hat{\mathbf{F}}_{c j}=-\hat{\mathbf{X}}_{o i} .
$$

The phase shifter-amplifier employed in the testing may vary $\mathbf{F}_{c j}$ continuously in both the amplitude and the phase angle; hence, Eq. (10) may 
be approximately satisfied by tuning within the force limits of the actuator. In practice, $\hat{\mathbf{X}}_{c i}$ in Eq. (8) is minimized by manually searching (tuning) through $\mathbf{F}_{c j}$ values. Note that the influence coefficient $\alpha_{i j}$ does not need to be measured to minimize $\hat{\mathbf{X}}_{c i}$. However, by applying a perturbation force, its measurement may expedite finding the optimum value for $\mathbf{F}_{c j}$. In the literature, this latter approach is referred to as active or feedforward balancing.

Additional displacement phasors may be nulled or minimized if multiple controllers are present. It is noteworthy that the displacements other than at degree-of-freedom $i$ in Eq. (8) may increase or decrease with the application of $\mathbf{F}_{\mathrm{cj}}$, as in influence coefficient flexible-rotor balancing. In practice, most displacements decrease, especially if a least-squares minimization procedure is employed.

\section{TEST FACILITY DESCRIPTION}

Figures 1 and 2 show a four-square spur gear facility at the NASA Lewis Research Center. The transmission is driven by a $7.45-\mathrm{kW}$ (10-hp) dc motor rated at $3500 \mathrm{rpm}$. A ring feeder is used to secure the 96-tooth gear to the low-speed shaft, while a key-way is used to mount the 24tooth gear to the high-speed shaft. There is a $0.875: 1.0$ gear tooth ratio from the motor to the input shaft and a 1.0:4.0 gear tooth ratio from the low-speed to the high-speed shaft. This gear configuration results in maximum shaft speeds of 4000 and $16000 \mathrm{rpm}$.

The spur gears are American Gear Manufacturing Association (AGMA) class 9 with a $20^{\circ}$ pressure angle, a diametral pitch of 16 , and a face width of $22.4 \mathrm{~mm}(0.88 \mathrm{im}$.). The low-speed shaft is separated into two pieces bolted together at a slotted flange. Pretwisting the two-piece lowspeed shaft allows different static preload torque to be locked into the shaft in or against the direction of rotation. A pretorque of $178 \mathrm{~N} \cdot \mathrm{m}(131$ $\mathrm{ft} \cdot \mathrm{lbs})$ circulates $74.6 \mathrm{~kW}(100 \mathrm{hp})$ through the system at a low shaft speed of $4000 \mathrm{rpm}$. A hydraulic system supplies lubrication to the bearings and gears through oil jets. An oil pressure regulator allows the gear lubrication to be adjusted or shut off. The rig is instrumented with 19 displacement probes, 8 accelerometers, 8 flowmeters, 8 pressure transducers, 6 thermocou-

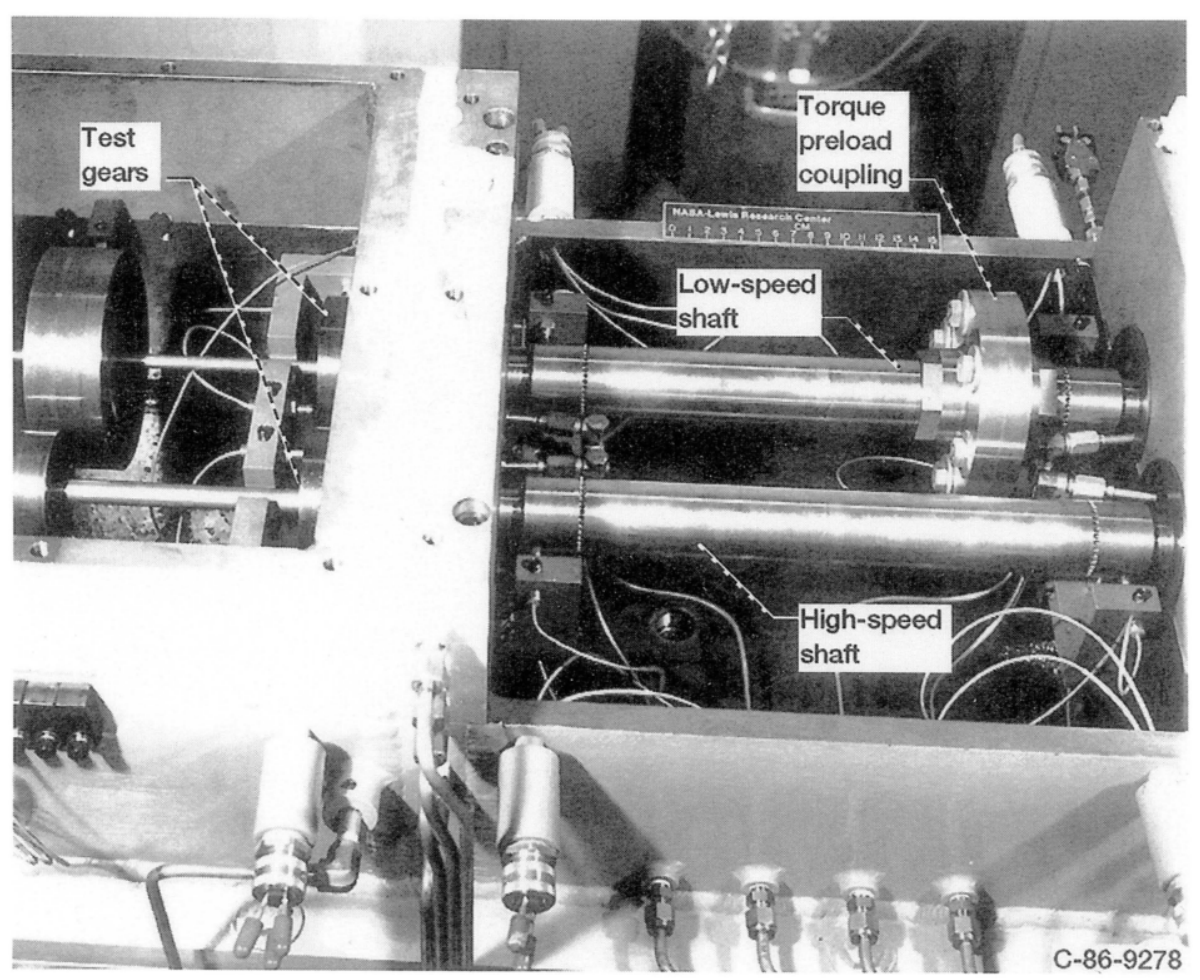

FIGURE 1 


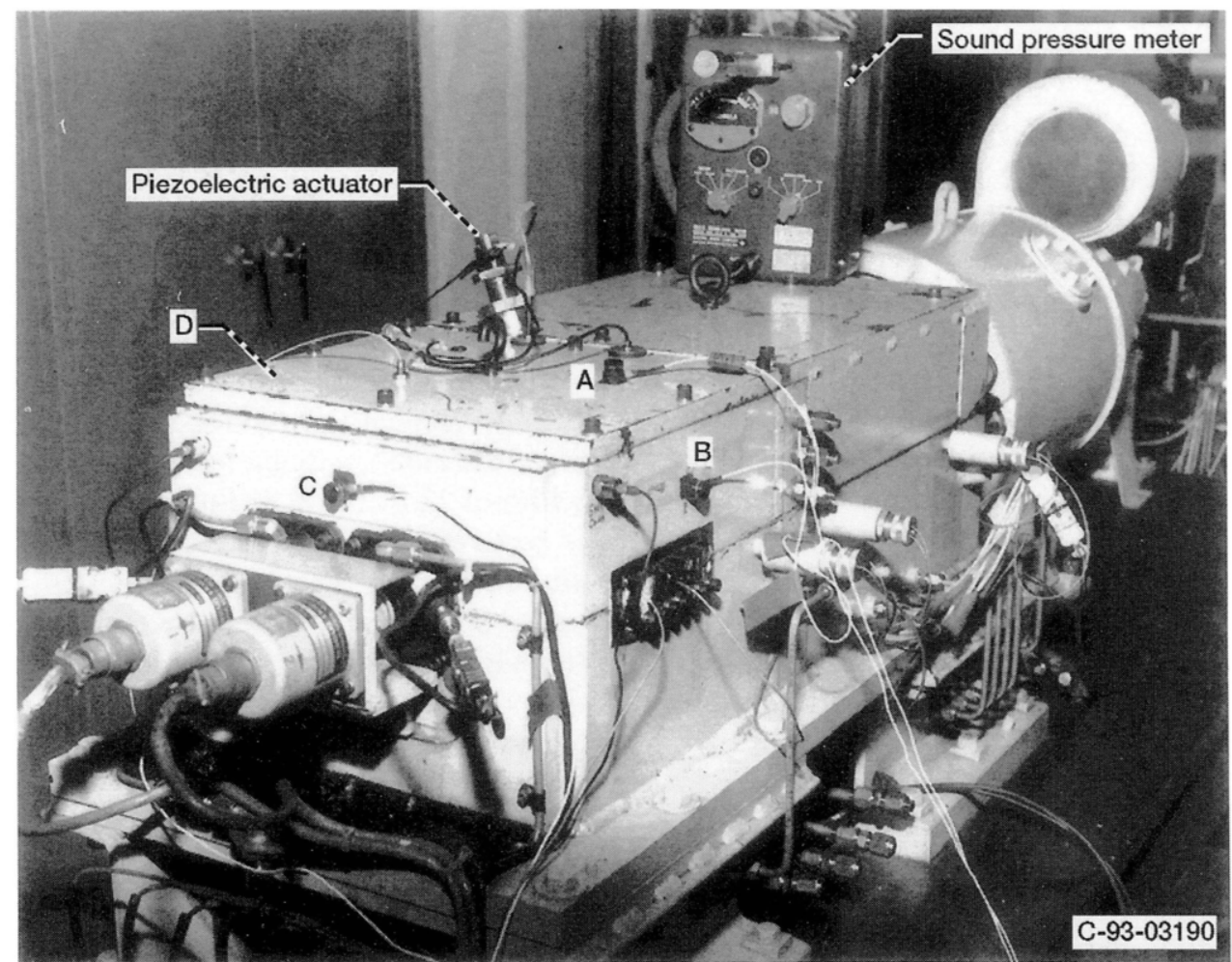

FIGURE 2

ples, 4 position encoders, and 1 sound pressure level meter.

Figure 2 shows the orientation of a piezoelectric actuator in the test rig. These piezoelectric actuators have a $3000-\mathrm{N}(675-\mathrm{lbs})$ force capacity and $30-\mu \mathrm{m}(0.00076$-in.) stroke. The control force produced by the actuator is transmitted to the shaft via duplex precision angular contact ball
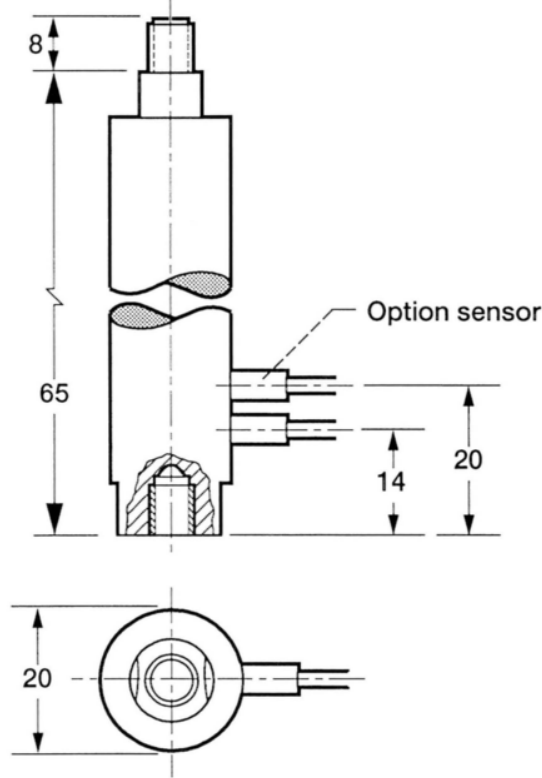

All dimensions in $\mathrm{mm}$
Operating voltage, $\mathrm{V} \ldots \ldots \ldots \ldots \ldots \ldots-20$ to +100 Admissible temperature range, ${ }^{\circ} \mathrm{C} \ldots \ldots \ldots-20$ to +80 Mechanical preload, $\mathrm{N}$............... 700 Nominal expansion at $+100 \mathrm{~V}, \mu \mathrm{m} \ldots \ldots \ldots \ldots . \ldots 30$

Maximum pushing force, $N \ldots \ldots \ldots \ldots . \ldots 3000$

Maximum pulling force, $N \ldots \ldots \ldots \ldots 700$

Electric capacitance, $\mu \mathrm{F} \ldots \ldots \ldots \ldots \ldots \ldots \ldots$

Stiffness, $\mathrm{N} / \mu \mathrm{m} \ldots \ldots \ldots \ldots \ldots \ldots \ldots \ldots \ldots \ldots \ldots$

Resonant frequency, $\mathrm{kHz} \ldots \ldots \ldots \ldots \ldots 12$

\section{FIGURE 3}




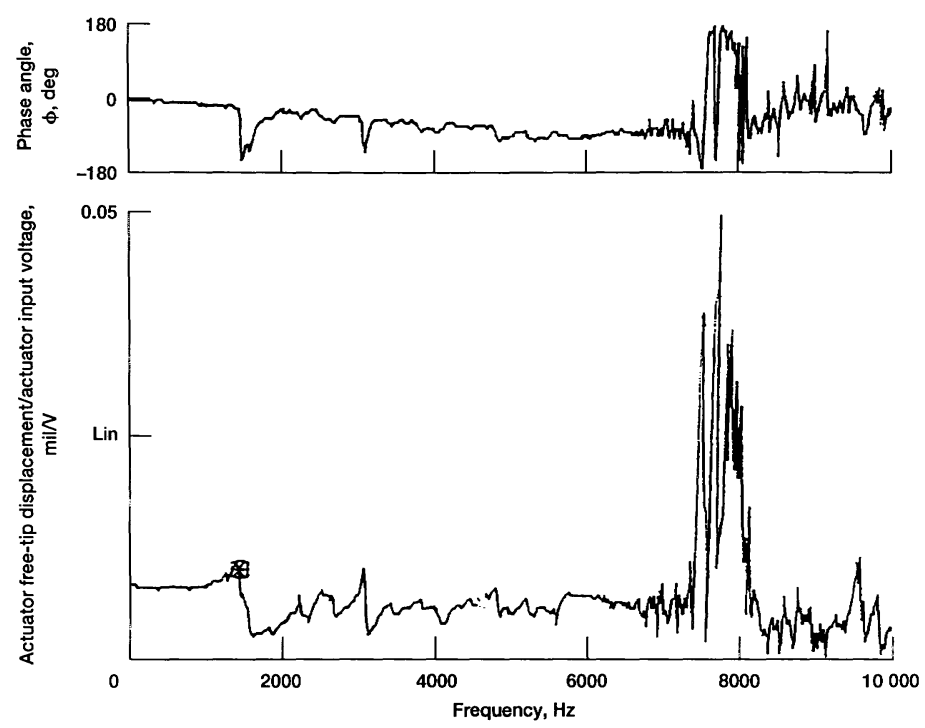

FIGURE 4

bearings, which are fitted in adapters with a $0.102-\mathrm{mm}(0.004-\mathrm{in}$.) radial clearance and a 19.1mm- (0.75-in.-) thick steel rig casing.

\section{ACTUATOR RESPONSE AND SETUP}

Figure 3 shows the piezoelectric actuator that was used in the feedforward control of the spur gear mesh vibration and the actuator's specifications. Figure 4 shows a piezoelectric actuator free-tip frequency response and Fig. 5 shows the frequency response of the actuator mounted in the test rig. The actuators' orientation relative to the gears and bearings is shown in Fig. 6. The actuators are mounted $20^{\circ}$ clockwise from the vertical axis of each shaft and collinear with the spur gear tooth contact force. Cone washers were used to support the bearing and center the shaft in the housing. A small accelerometer is mounted at the actuator tip.

The block diagram representation of the control loop is shown in Fig. 7. A displacement probe gear tooth signal is sent to the analog phase

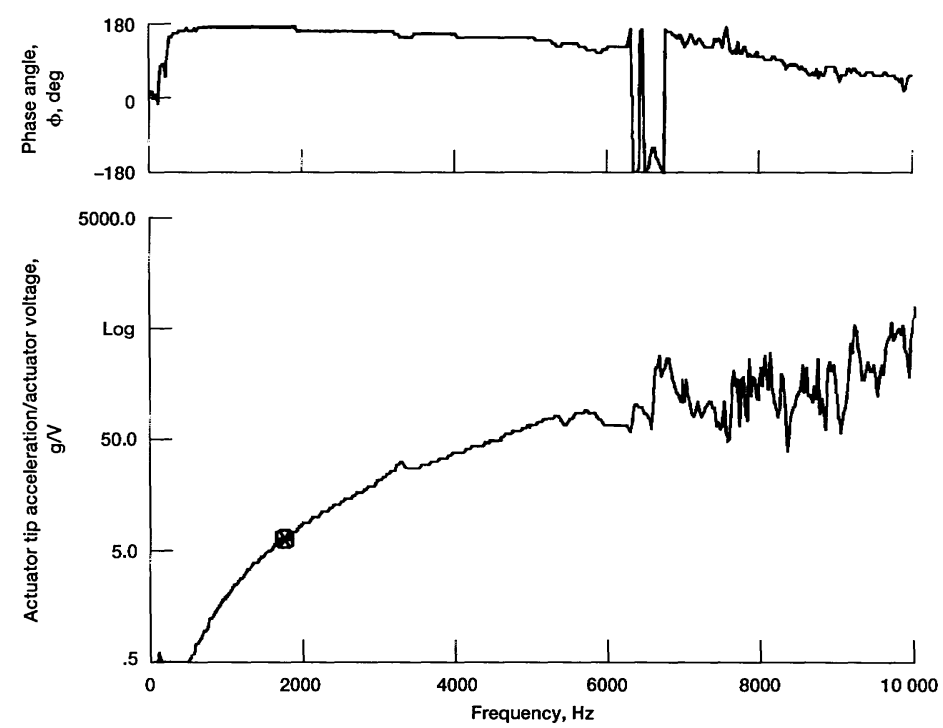

FIGURE 5 


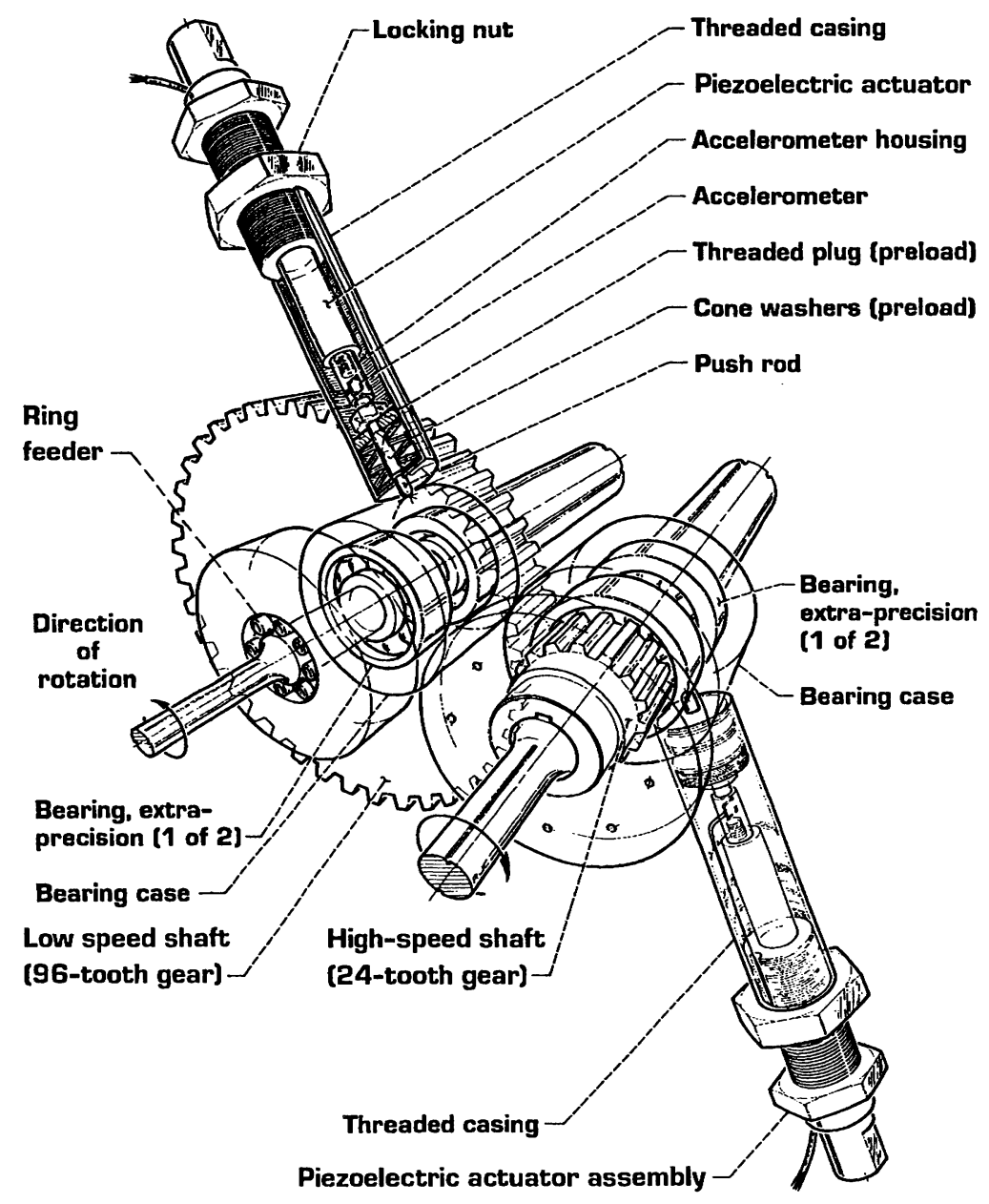

FIGURE 6

shifter, which has a frequency and a phase adjustment dial. The phase shifter converts the gear tooth signal to the feedforward signal, which is a sinusoidal signal at the same frequency. The phase is manually adjusted and a signal inverter is used to ensure a $360^{\circ}$ adjustment range. The feedforward signal amplitude is manually adjusted through the isolation amplifier. An oscilloscope is used to monitor the gear tooth and feedforward signals. Figure 8 shows the gear tooth, feedforward, and one pulse per revolution signal on the oscilloscope. The feedforward signal voltage and current are monitored by analog meters and then sent to the piezoelectric actuators.

A four-channel dynamic signal analyzer monitors the frequency response of four accelerometers mounted on the transmission casing (Fig. 2). Test conditions were adjusted to maximize the gear mesh vibration before applying the feedforward control. The phase and amplitudes of the feedforward signals are adjusted to minimize the gear mesh frequency component amplitudes.

\section{ROTATING RIG TEST RESULTS}

Feedforward control using piezoelectric actuators was applied to the transmission rig under different torque, speed, and actuator conditions.

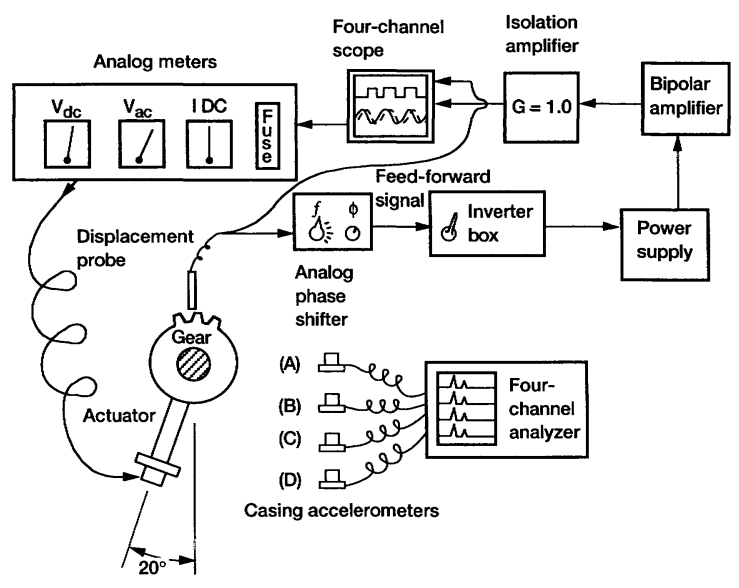

FIGURE 7 

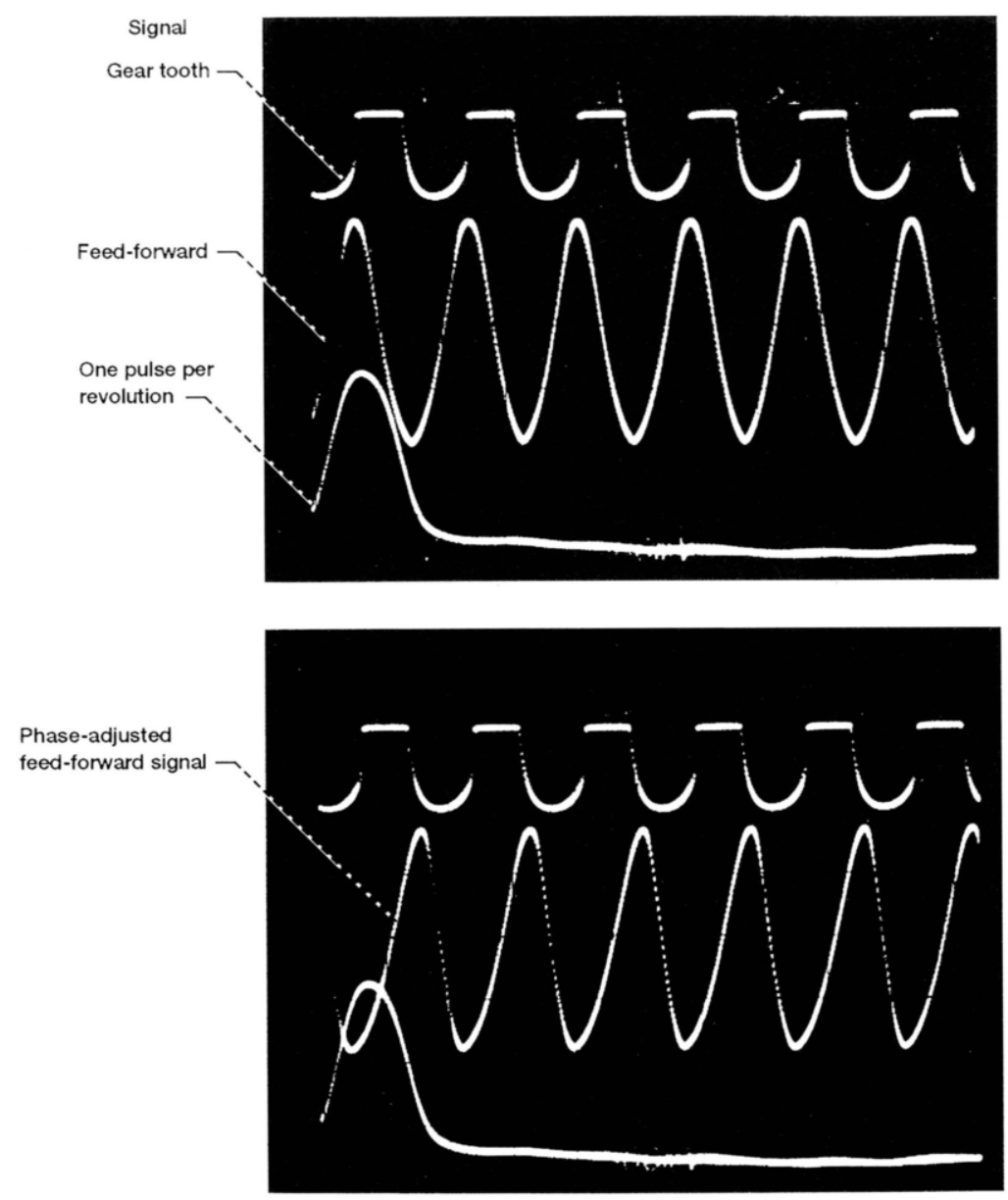

FIGURE 8
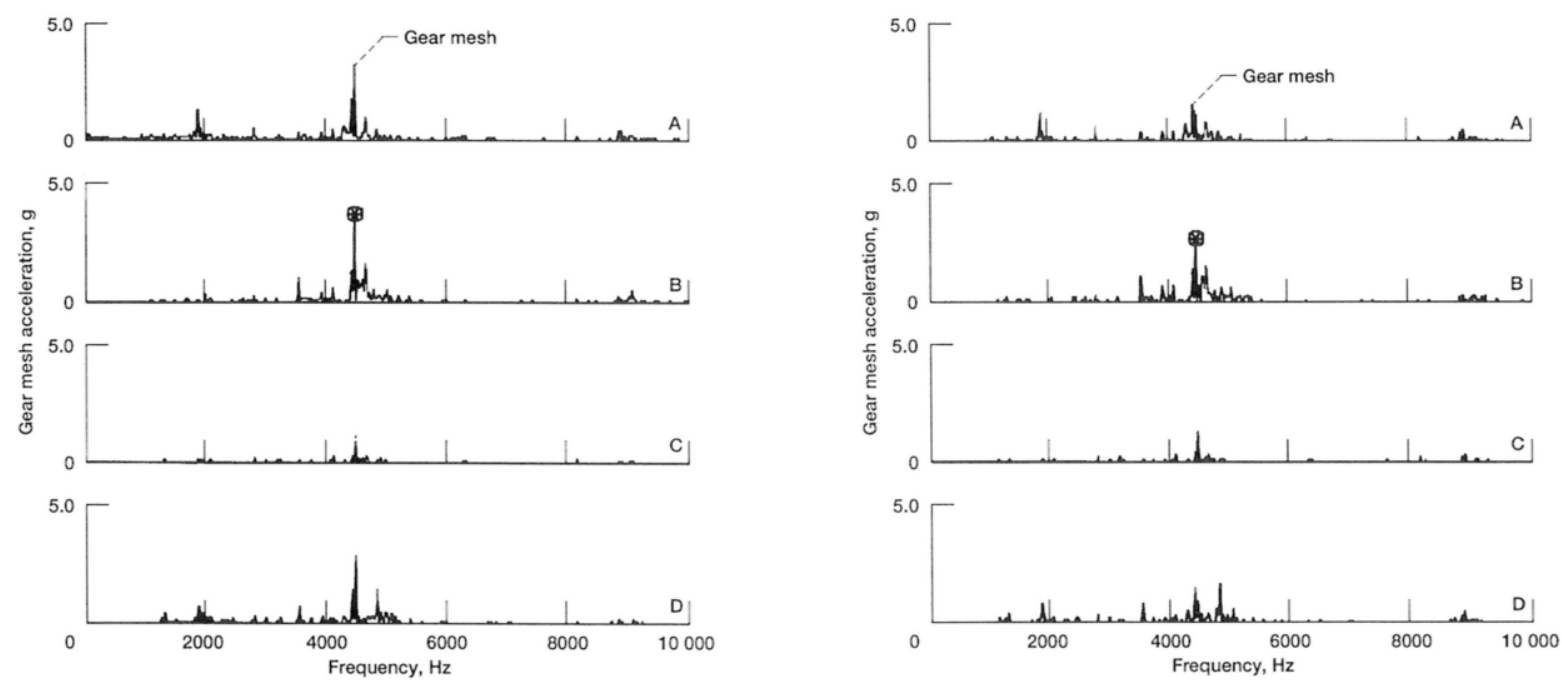

FIGURE 9

FIGURE 10 
Table 1. Casing Accelerometer Vibration for Low-Speed Shaft Actuator

\begin{tabular}{|c|c|c|c|c|c|c|}
\hline & & & & & Gear & Vibration \\
\hline & & $\begin{array}{l}\text { Shaft } \\
\text { Speed }^{\text {a }}\end{array}$ & & $\begin{array}{l}\text { Gear Mesh } \\
\text { Frequency }\end{array}$ & Feed & Control \\
\hline $\mathrm{N} \cdot \mathrm{m}$ & $\mathrm{ft} \cdot \mathrm{lb}$ & (rpm) & Accelerometer & $(\mathrm{Hz})$ & With & Without \\
\hline-149 & 110 & 1600 & A & 2550 & 0.5 & 0.8 \\
\hline-149 & 110 & 1600 & B & 2550 & 1.8 & 2.0 \\
\hline-149 & 110 & 1943 & A & 3100 & 0.4 & 0.8 \\
\hline-149 & 110 & 1943 & B & 3100 & 1.2 & 2.6 \\
\hline-149 & 110 & 2267 & A & 3625 & 0.5 & 1.1 \\
\hline-149 & 110 & 2267 & B & 3625 & 2.3 & 3.4 \\
\hline+149 & +110 & 1829 & A & 2925 & 1.1 & 2.8 \\
\hline+149 & +110 & 1829 & B & 2925 & 1.0 & 0.0 \\
\hline+149 & +110 & 1942 & A & 3100 & 0.7 & 2.7 \\
\hline+149 & +110 & 1942 & B & 3100 & 1.0 & 0.9 \\
\hline
\end{tabular}

Gear lubrication, $75 \mathrm{psig}$; torque, $\pm 149 \mathrm{~N} \cdot \mathrm{m}( \pm 110 \mathrm{ft} \cdot \mathrm{lb})$.

${ }^{a}$ Low-speed shaft.

Test speeds that produced high gear mesh components were chosen for the feedforward tests (Tables 1-3). Feedforward control was tested using a single actuator on the low-speed shaft and using two in-phase actuators (one for each shaft). Figures 9 and 10 show the casing vibration spectra before and after the feedforward loop was applied to the low-speed actuator. These figures show a $27 \%$ reduction in gear mesh vibration at $4450 \mathrm{~Hz}$. The sound pressure spectra with and without low-speed shaft actuator feedforward control shows a $22 \%$ reduction in the gear mesh vibration amplitude at $4650 \mathrm{~Hz}$ as seen in Figs. 11 and 12 .

Table 2. Gear Mesh Variation for Two-Actuator System

\begin{tabular}{|c|c|c|c|c|}
\hline \multirow{3}{*}{$\begin{array}{l}\text { Shaft } \\
\text { Speed }^{\mathrm{a}} \\
\text { (rpm) }\end{array}$} & \multirow[b]{3}{*}{ Accelerometer } & \multirow{3}{*}{$\begin{array}{c}\text { Gear Mesh } \\
\text { Frequency } \\
(\mathrm{Hz})\end{array}$} & \multirow{2}{*}{\multicolumn{2}{|c|}{$\begin{array}{l}\text { Gear Mesh Vibration } \\
(g)\end{array}$}} \\
\hline & & & & \\
\hline & & & With & Without \\
\hline 1942 & A & 3100 & 1.6 & 2.0 \\
\hline 1942 & B & 3100 & 0.7 & 0.4 \\
\hline 2171 & A & 3475 & 2.0 & 3.8 \\
\hline 2171 & B & 3475 & 5.0 & 4.6 \\
\hline 2344 & A & 3750 & 1.7 & 4.3 \\
\hline 2344 & B & 3750 & 2.5 & 5.0 \\
\hline 2628 & A & 4200 & 4.6 & 7.0 \\
\hline 2628 & B & 4200 & 4.8 & 2.3 \\
\hline 2688 & A & 4300 & 1.2 & 5.0 \\
\hline 2688 & B & 4300 & 5.1 & 3.0 \\
\hline
\end{tabular}

Gear lubrication, $75 \mathrm{psig}$; preload torque, $+194 \mathrm{~N} \cdot \mathrm{m}(143 \mathrm{ft} \cdot \mathrm{lb})$.

a Low-speed shaft. 
Table 3. Gear Mesh Vibration with Feedforward to Low-Speed Shaft Actuator

\begin{tabular}{|c|c|c|c|c|}
\hline \multirow{3}{*}{$\begin{array}{l}\text { Shaft } \\
\text { Speed }^{\mathrm{a}} \\
(\mathrm{rpm})\end{array}$} & \multirow{3}{*}{$\begin{array}{c}\text { Gear Mesh } \\
\text { Frequency } \\
(\mathrm{Hz})\end{array}$} & $\mathrm{Ge}$ & ion & \multirow{3}{*}{$\begin{array}{c}\text { Gear } \\
\text { Lubrication } \\
\text { (psig) }\end{array}$} \\
\hline & & \multicolumn{2}{|c|}{ Accelerometer } & \\
\hline & & A & B & \\
\hline 1600 & 2550 & 0.8 & 1.6 & 0 \\
\hline 1600 & 2550 & 0.8 & 1.8 & 75 \\
\hline 1600 & 2550 & 1.0 & 1.1 & 175 \\
\hline 1600 & 2550 & 0.6 & 1.4 & 250 \\
\hline 1943 & 3100 & 1.0 & 2.4 & 0 \\
\hline 1943 & 3100 & 0.8 & 2.6 & 75 \\
\hline 1943 & 3100 & 1.2 & 2.2 & 175 \\
\hline 1943 & 3100 & 1.1 & 2.3 & 250 \\
\hline 2267 & 3625 & 1.1 & 2.5 & 0 \\
\hline 2267 & 3625 & 1.0 & 3.4 & 75 \\
\hline 2267 & 3625 & 1.8 & 3.6 & 175 \\
\hline 2267 & 3625 & 1.0 & 2.6 & 250 \\
\hline
\end{tabular}

Torque, $-149, \mathrm{~N} \cdot \mathrm{m}(-110 \mathrm{ft} \cdot \mathrm{lb})$.

${ }^{a}$ Low-speed shaft.

Figure 13 shows that gear mesh vibration and the actuator current increase as a function of the actuator voltage; Fig. 14 shows the effect of the feedforward phase angle adjustment on the casing accelerometer $\mathrm{A}$ at a $4650-\mathrm{Hz}$ gear mesh vibration and is compared with the no-control accelerometer A signal.
Table 1 presents the test conditions and the casing vibrations with and without control at four different speeds and two different torques using the low-speed shaft actuator only. As shown in the figure, gear mesh vibration was reduced as much as $74 \%$. Casing accelerometer vibration spectra with and without feedforward control for

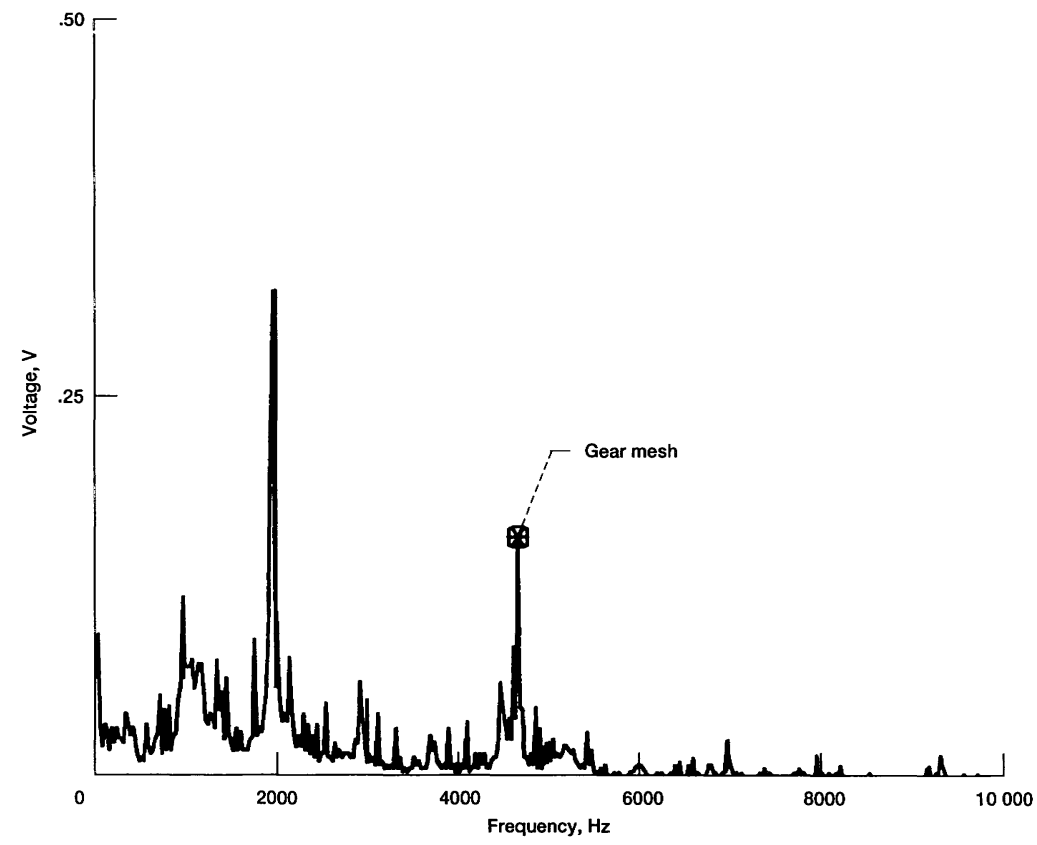

FIGURE 11 


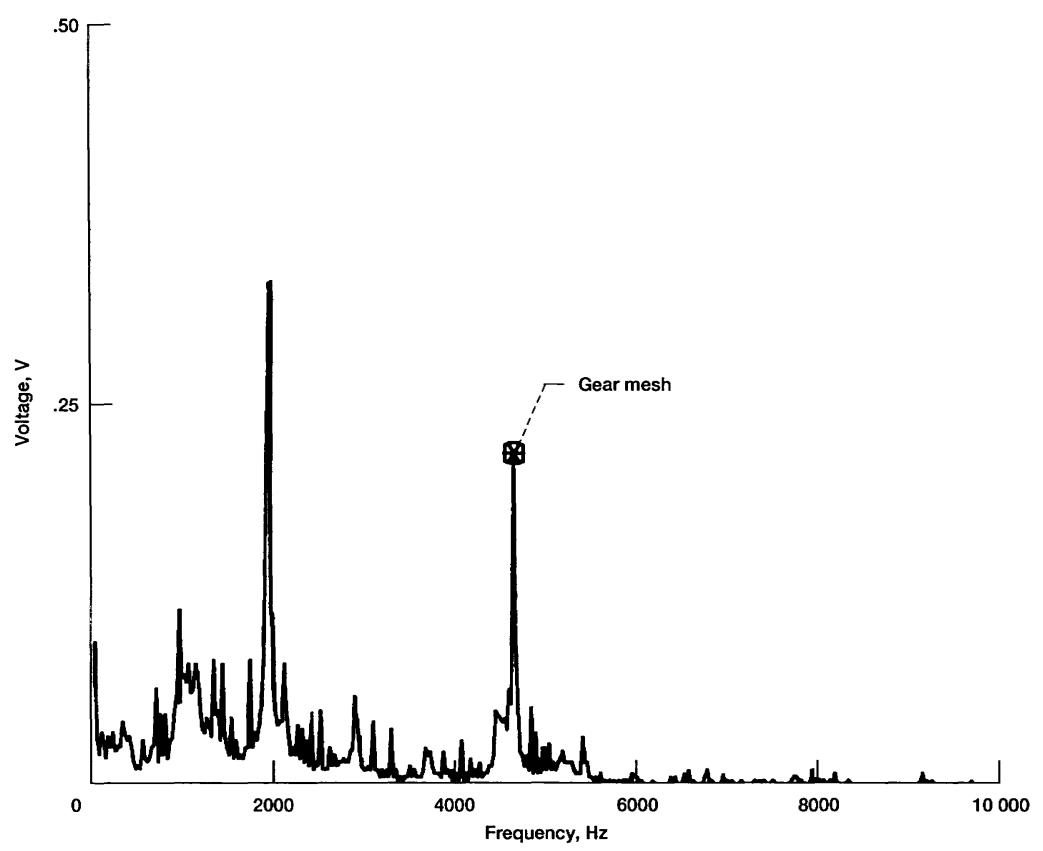

FIGURE 12

a one-actuator system with a $+149-N \cdot m(+110-$ $\mathrm{ft} \cdot \mathrm{lb})$ preload torque are shown in Figs. 15 and 16 and in Table 1 . The results indicate very significant vibration reductions at $\mathrm{A}, \mathrm{B}$, and $\mathrm{C}$. Table 2 presents the results for the condition in which a $+194-N \cdot m(143-\mathrm{ft} \cdot \mathrm{lb})$ preload torque was applied to a two-actuator system. Figures 17 and 18 and Table 2 show casing accelerometer vibration spectra with and without control for a two-actua- tor system with a $+194-N \cdot m(143-\mathrm{ft} \cdot \mathrm{lb})$ preload. These results also show very effective vibration control using the feedforward approach.

Comparing a one-actuator system with a twoactuator system reveals a $74 \%$ vibration reduction with $\mathrm{a}+149-N \cdot m(110-\mathrm{ft} \cdot \mathrm{lb})$ preload for the one-actuator system and a $76 \%$ reduction with a $+194-N \cdot m(143-\mathrm{ft} \cdot \mathrm{lb})$ preload for the two-actuator system. The vibration at some accelerome-

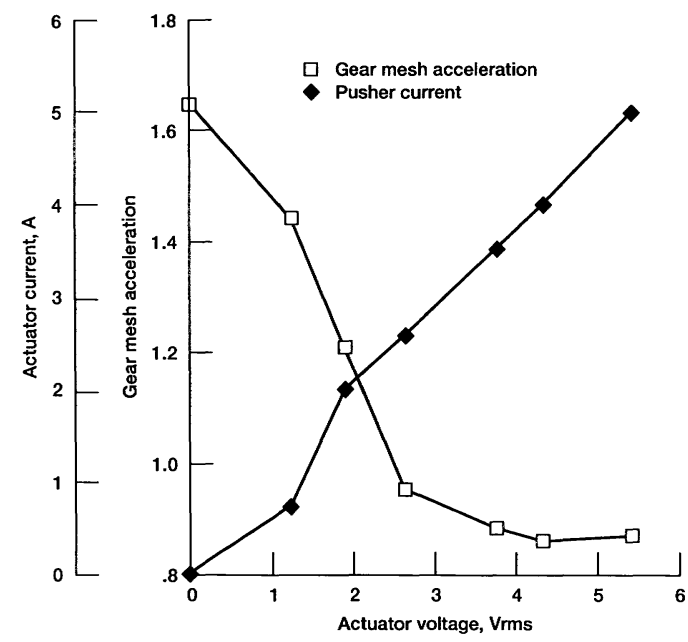

FIGURE 13

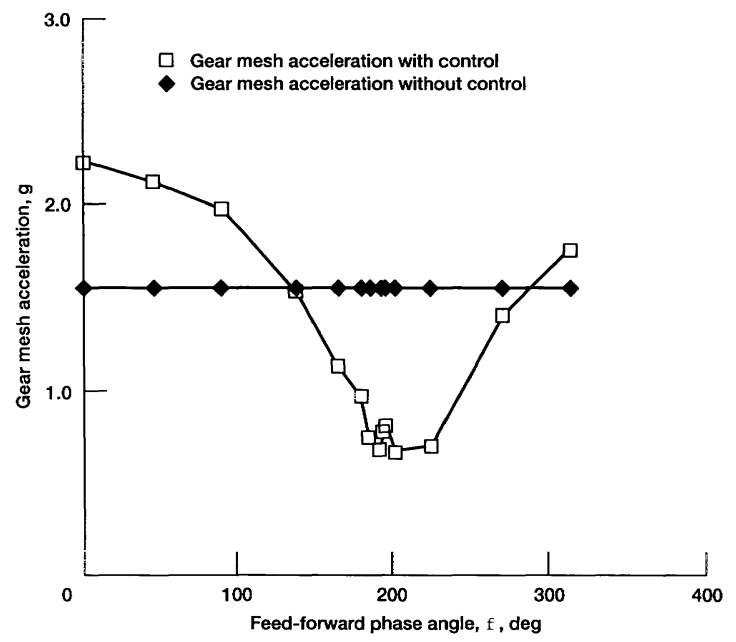

FIGURE 14 

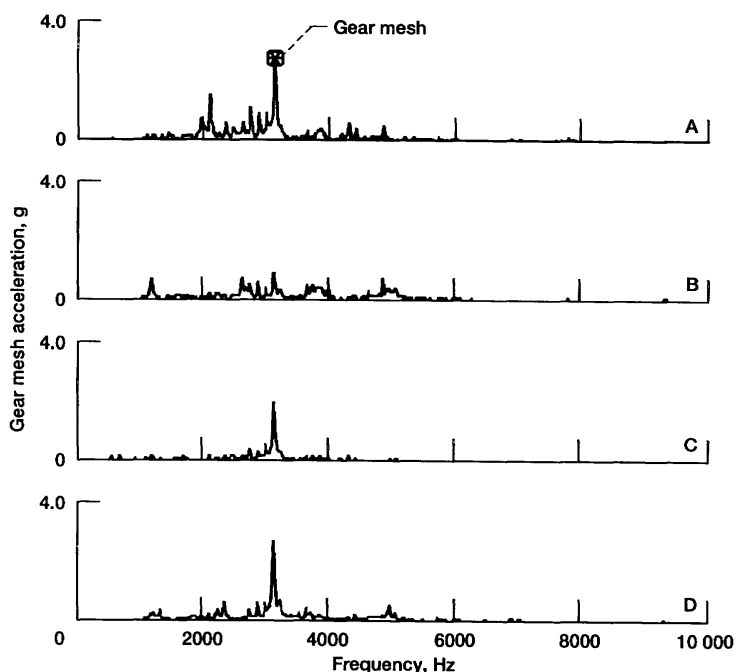

FIGURE 15

ters actually increases with control (Table 2). This result is similar to flexible rotor balancing and indicates that additional independently controlled actuators may be required to suppress vibrations at many locations. The vibration data of tests with different gear oil lubrication pressure is summarized in Table 3. This test was performed to generate high levels of gear mesh vibration; however, the results show little change in vibration amplitude; therefore feedforward tests were not conducted.
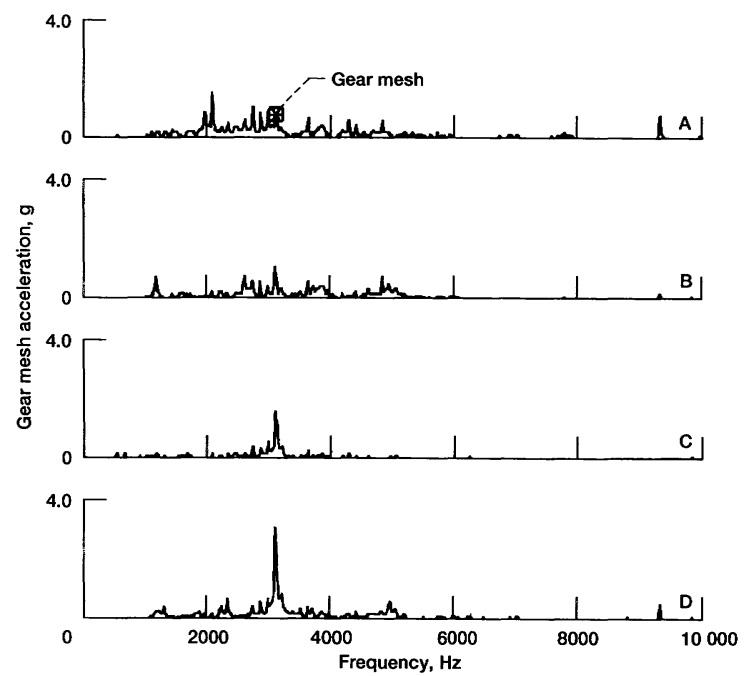

FIGURE 16
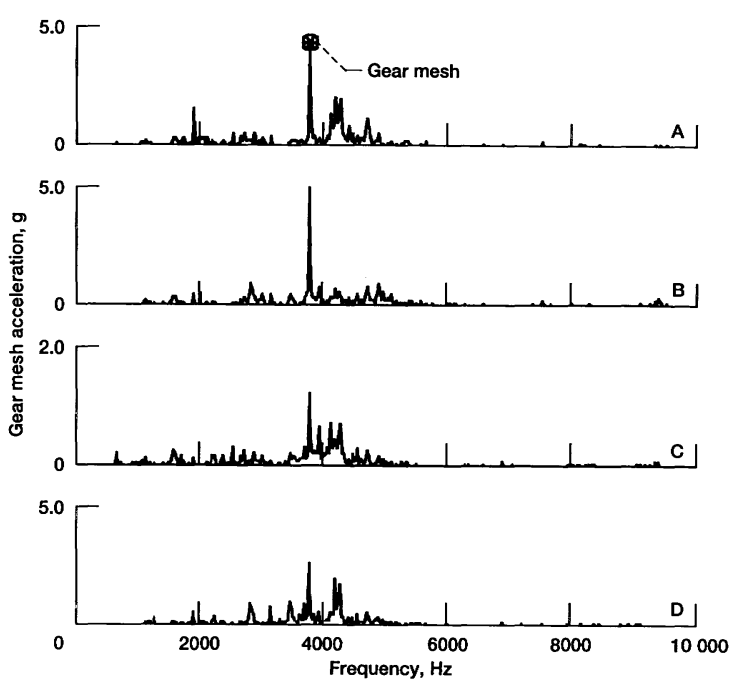

FIGURE 17

\section{SUMMARY OF RESULTS}

Previous tests applied piezoelectric actuators to control rotor vibrations at low frequencies of $100-250 \mathrm{~Hz}$. The results obtained in this study show that a piezoelectric actuator with a feedforward control can reduce the gear mesh vibration amplitude up to $75 \%$ for frequencies up to $4500 \mathrm{~Hz}$. Experimental results showed a significant reduction in gear mesh vibration at different speeds and torques. Future work will incorpo-
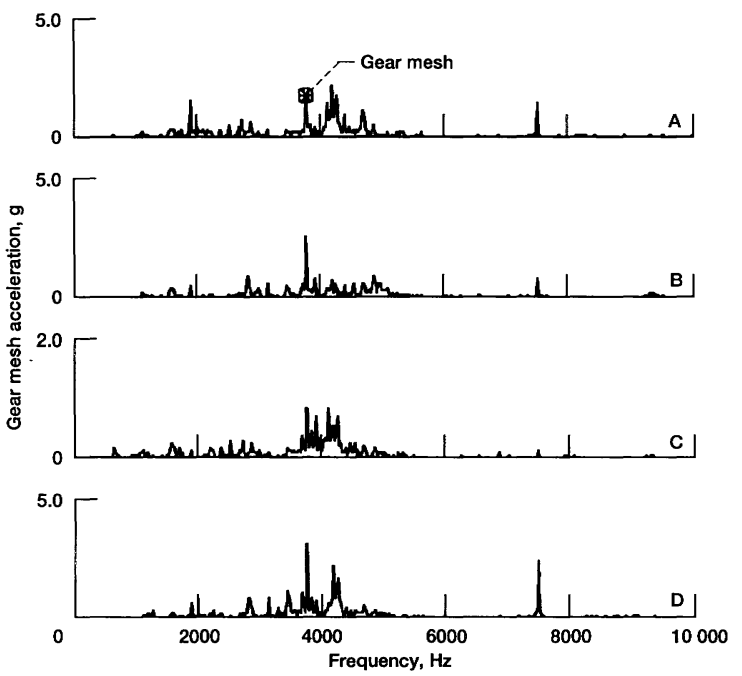

FIGURE 18 
rate independent control for more actuators, development of a digital feedforward control, and the application of an actuator with an increased stroke.

The authors thank the NASA Lewis Research Center and the U.S. Army Vehicle Propulsion Directorate at Lewis for funding this research. Sincere appreciation is also extended to Mr. Jeff Hamman and Mr. John Ropchock (NASA Lewis) for technician support.

\section{REFERENCES}

Ariga, K., Abe, T., Yokoyama, Y., and Enomoto, Y., 1992, "Reduction of Transaxle Gear Noise by Gear Train Modification," Presented at the Worldwide Passenger Car Conference, Dearborn, MI, September 28-October 1.

Botsford, G. L., 1980, "Reducing Gear Noise by Vibration Damping," in G. G. Maling, Internoise 80: Noise Control for the 80s, Proceedings of the Ninth International Conference on Noise Control Engineering, Miami, FL, December 8-10, International
Institute of Noise Control Engineering, Poughkeepsie, NY.

Choy, F. K., Ruan, Y. F., Zakrajsek, J. J., and Oswald, F. B., 1993, "Modal Simulation of Gear Box Vibration with Experimental Correlation," Journal of Propulsion and Power, Vol. 9, pp. 301-306.

Mathew, J., and Alfredson, R. J., 1987, "Monitoring Gearbox Vibration Operating Under Steady Conditions," presented at the ASME 11th Biennial Conference on Mechanical Vibration and Noise, Boston, MA, September 27-30.

Nagamatsu, A., Michimura, S., and Ishihara, A., 1979, "Vibration of High Speed Rotating Machine," Bulletin of the Japan Society of Precision Engineering, Vol. 13, pp. 183-188.

Palazzolo, A. B., Jagannathan, S., Kascak, A. F., Montague, G. T., and Kiraly, J. L., 1993, "Hybrid Active Control of Rotorbearing Systems Using Piezoelectric Actuators," Journal of Vibration, Vol. 38, pp. 227-240.

Ren, X., Xu, M., and Gu, J., 1990, "Gear Vibration Control with Viscoelastic Damping Material in Aeroengine,"' Journal of Aerospace Power, Vol. 5, pp. 48-52.

Umezawa, K., Houjoh, H., and Maki, H., 1988, “Estimation of the Vibration of in Service Gears by Monitoring the Exterior Vibration,' JSME International Journal, Ser. III, Vol. 31, pp. 588-592. 

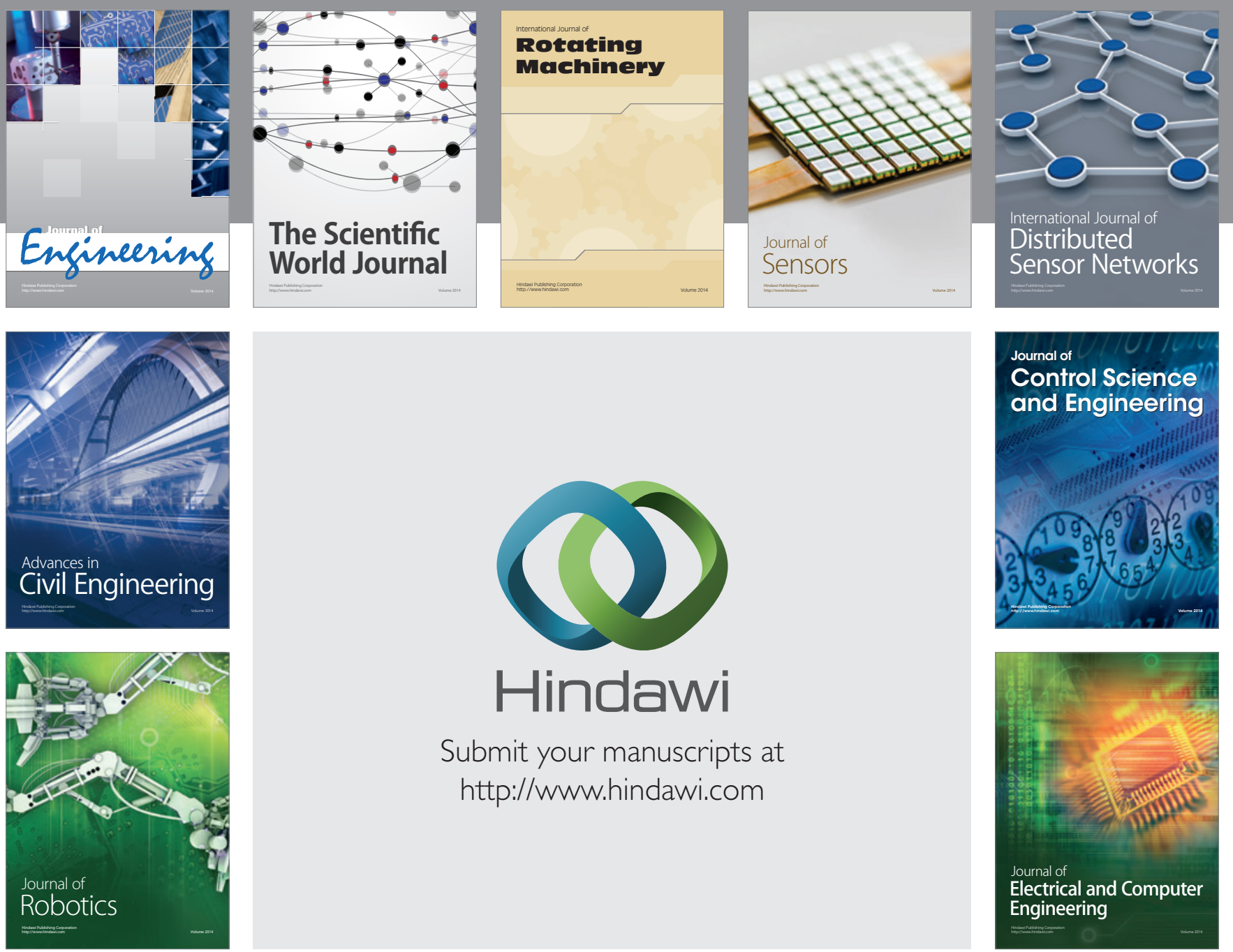

Submit your manuscripts at

http://www.hindawi.com
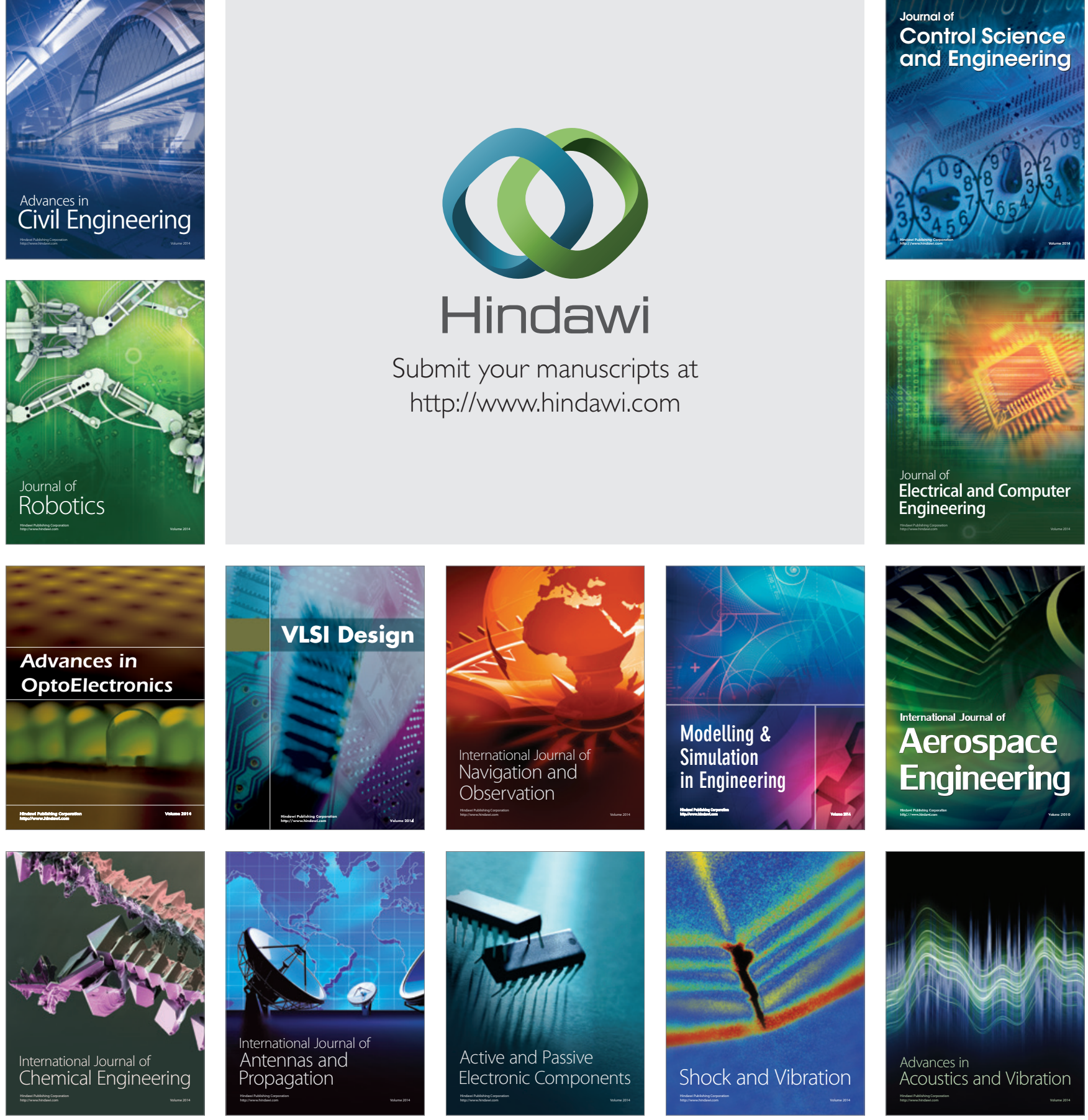